\title{
COPD, Depression and COVID-19 Pandemic: A Harrowing, Demoralizing and Deleterious Triad
}

Iqbal Akhtar Khan ${ }^{1 *}$ and Hamza Iltaf Malik ${ }^{2}$

${ }^{1}$ MBBS DTM FACTM PhD, Independent Scholar, Lahore-54792, Pakistan.

${ }^{2} \mathrm{MBBS}$, Northampton General Hospital, Cliftonville, Northampton, United Kingdom.

*Corresponding Author: Iqbal Akhtar Khan, MBBS DTM FACTM PhD, Independent Scholar, Lahore-54792, Pakistan.

Received Date: July 01, 2021; Accepted Date: September 10, 2021; Published Date: September 23, 2021

Citation: Iqbal Akhtar Khan and Hamza Iltaf Malik (2021) COPD, Depression and COVID-19 Pandemic: A Harrowing, Demoralizing and Deleterious Triad. Clinical Medical Reviews and Reports. 3(8); DOI: 10.31579/2690-8794/095

Copyright: (c) 2021, Iqbal Akhtar Khan, This is an open access article distributed under the Creative Commons Attribution License, which permits unrestricted use, distribution, and reproduction in any medium, provided the original work is properly cited.

\begin{abstract}
COPD is a highly incapacitating global public health problem, with pulmonary and extra-pulmonary manifestations and usually associated with significant concomitant chronic diseases. With enhanced understanding, it has extensively been reported as a complex, heterogeneous and dynamic disease affecting patients' health beyond pulmones.

Depression, with prevalence of 322 million people, is a major contributor to the overall global burden of disease. In various epidemiological and clinical studies, its prevalence among patients with COPD varies from $18 \%$ to $80 \%$. This deadly duo leads to excessive health care utilization rates and costs including increased rates of exacerbation, sub-optimal adherence to prescribed medications, increased hospital admissions, longer hospital stays and increased hospital readmissions. Moreover, there is increased risk of suicidal ideation, suicidal attempts, and suicidal drug overdose. It is a pity that, in significant cases, the co-morbidity remains under-recognized and under-treated.

The impact of prevailing COVID 19 pandemic, on the dual burden of COPD and depression, and possible remedial measures including "The 6 ways to boost one's well-being-by Mental Heath UK, "The Living with the Times" toolkit--by WHO" and innovative add-ons like Dance Movement Therapy and Musical Engagement Therapy have been discussed.

Key words: COPD, depression, COVID19 pandemic, social distancing, shielding, duicidal ideation
\end{abstract}

\section{Introduction}

Dr. William Briscoe, the then Head of the Pulmonary Division New York Hospital-Cornell Medical Center, was the first person to use the term "Chronic obstructive pulmonary disease (COPD), as an umbrella term for chronic bronchitis, emphysema, and chronic asthmatic bronchitis, at the 9th Aspen Emphysema Conference, in 1965. With enhanced understanding, COPD has extensively been reported as a complex [1], heterogeneous [2] and dynamic [3] disease affecting patients' health beyond pulmones.

Houben-Wilke et al argue that COPD stands for "Complex obstructive pulmonary disease" [4]. Where as a variety of intra- and extra-pulmonary components and considerable variability between individuals have been reported, the present study deals with depression co-existing with COPD. The consequences of social isolation and shielding on such patients, in the prevailing COVID-19 pandemic, are also being discussed.

\section{Depression}

"In our society that sets high standards of perfection to be ok and wins, the depressed is commonly considered as an outsider, a marginalized person unable to be in line with standards and rhythms fast and competitive of the time we live".

Romina Tavormina \& Maurilio Tavormina [5]

Depression is a leading cause of ill health and disability worldwide and is a major contributor to the overall global burden of disease. According to the latest estimates from WHO, 322 million people are now living with depression [6]. Despite its enormous clinical and public health impact, depressive illness is often under-diagnosed and under-scored, particularly when it co-exists with physical ailment. This often causes great distress for patients who have mistakenly assumed that symptoms, such as weakness or fatigue, are due to an underlying medical condition [7].

Depression and COPD: Dual Burden 
"Depression is the largest cause of mental ill health worldwide, described as a "global burden" or a "global crisis" -----World Federation for Mental Health (WFMH, 2012)

Whereas depression is a common emotional disturbance, its association with chronic diseases has been well documented in literature. The mechanisms responsible for depression in patients with COPD are likely to be multifactorial [8]. "Reactive" depression associated with declining health status is more common [9]. In various epidemiological and clinical studies, its prevalence among patients with COPD varies from $18 \%$ to $80 \%$ (10]. In United States alone, the population with COPD has the highest prevalence of depression amongst the three chronic conditions that affect 60 million people (diabetes, heart disease, and COPD) [11].

In a randomized case control Dutch study, it was found that the prevalence of depression in COPD patients, with severe airways obstruction (FEV1 $<50 \%$ ), was $25 \%$ and that they had a 2.5 times greater risk of depression than controls. However, in patients with mild (FEV1 80\%) to moderate (FEV1 50-80\%) COPD, no increased risk for depression was seen [12]. In the nested case-control analysis, using the UK-based General Practice Research Database, the patients with severe COPD had the highest risk of developing depression [13]. It has been proven that the more advanced the disease is, the greater the risk of depressive symptoms [14], with women being more prone to depression [15].

In a Polish study, it was found that the incidence of depression was high in patients who had recently experienced an exacerbation (AECOPD) [16].In a US retrospective cohort on COPD patients of 40 years and above , it was found that COPD patients with comorbid depression were 77\% more likely to have a COPD-related hospitalization, $48 \%$ more likely to have an ER visit, and 60\% more likely to have a hospitalization/ ER visit compared to the COPD-Only cohort [17].

Of note, depression is a strong predictor for mortality in patients with COPD, among hospitalized [18] and community patients [19]. In a Dutch study, on hospitalized stable patients with COPD, the depressive symptoms were associated with mortality independent of other factors including male sex, older age and lower peak workload (Wpeak) [20]. Atlantis et al showed that the dual burden increased the risk of mortality by $83 \%$ compared to the COPD patients without comorbid depression [21].

Studies, at various settings, suggest that depression in COPD leads to excessive health care utilization rates and costs including increased risk of AECOPD [ 22], non-compliance with medical treatment [[23], increased hospital admission, [24], longer hospital stay, [18] and increased hospital readmission. [25]. In a Romanian exploratory analysis, derived from an ongoing cross-sectional study, carried out to evaluate levels of fatigue and impact on health-related quality of life/health status in patients with COPD, fatigue was the most common detected 'general' symptom and also one of the most under-recognised and under-treated manifestation of this malady [26].

Suicidal Ideation, Suicidal Attempts and Suicidal Drug Overdose

"A human being can survive almost anything, as long as she sees the end in sight. But depression is so insidious, and it compounds daily, that it's impossible to ever see the end".

\section{Elizabeth Lee Wurtzel (1967-2020)--'Prozac Nation’ Author}

Depression is a well-established risk factor for suicide. In a large casecontrol study in Family Practices in England, the relative risk of suicide was significantly elevated among patients with COPD compared with those without major chronic illnesses (3.1\% versus $1.9 \%$, respectively) [27]. In The DEPREPOC (Depression in COPD), an observational, crosssectional, multi-center Spanish study designed to analyze the prevalence of depression in COPD patients and to identify factors associated with depression, moderate to severe depression was associated with suicidal ideation [28].

While analyzing suicidal risk, in an epidemiological study in adults ages 18 and older in the United States, it was found that $27.2 \%$ of COPD patients had suicidal ideation as compared to $19.6 \%$ of subjects without COPD. The history of suicide attempt was significant (15.0\% for COPD patients, $6.6 \%$ for subjects without COPD [29]. A mixed-methods US study, to examine the prevalence and correlates of suicidal ideation in patients with stable moderate to very severe COPD, revealed that this was common in COPD, may occur disproportionately in women, can persist despite mental health treatment, and had complex relationships with both health and life events. [30]. COPD patients with depression had 13.6- and 10.0-fold higher risks of suicidal attempts and suicidal drug overdose, respectively, than did controls, in a Taiwanese study. The risk was more pronounced in patients aged less than 50 years [31]

In a Korean study, based on data from the Fourth Korean National Health and Nutrition Examination Survey (KNHANES IV \& V), suicidal ideation was reported by $16.0 \%$ of patients in stages I and II, by $23.8 \%$ of those in stages III and IV and by $15.7 \%$ of controls. The suicidal attempts were reported by $0.6 \%$ of patients in stages I and II, by $2.6 \%$ of those in stages III and IV and by $1.0 \%$ of controls [32]. It should be a matter of serious concern that an association between history of hospitalization and increased suicidal risk has been reported. In a Nested case-control study, based on data from five Danish national, medical, and administrative registries/databases, it was found that patients with a history of hospitalization with COPD were at a significantly increased risk of suicide compared with individuals without such a history. The association was more pronounced in women than in men and in individuals aged 6195 years than the younger group and in persons with no history of psychiatric illness [33].

\section{Repercussion of the Dual Burden}

The epidemiological and clinical studies reveal that inadequately treated malady is associated with worse outcomes. The deleterious effects include sub-optimal adherence to pharmacotherapy, repeated episodes of AECOPD, increased hospitalization, prolonged length of stay, readmissions and subsequently increased burden to healthcare system, more pronounced in resource limited countries where the budget is already over-run. Moreover, despite significantly higher toll of depressive disorders in patients with COPD than controls, the low percentage of such patients seeking psychiatric consultation suggests that there is an unmet need in the psychiatric care of COPD patients [34]. While the background information that the psychological status plays an intrinsic role in the overall well- being is ignored, such patients are regularly overlooked, often remain undiagnosed and rarely get access to adequate treatment [35]. In view of the severity of the problem, early detection and prompt intervention is crucial. Of imp, the UK NICE Guidelines for COPD advise that patients should be offered psychological therapies before they are prescribed anti-depressants [36]. Interestingly, "Evaluation of COPD Longitudinally to Identify Predictive Surrogate Endpoints (ECLIPSE) Study" found a 30\% decrease in mortality in patients with COPD who were using mental health services, compared with those who were not referred to specialist services but were treated in primary care [37].

Impact of COVID 19 Pandemic on Depression associated COPD 
"Although the COVID-19 crisis is, in the first instance, a physical health crisis, it has the seeds of a major mental health crisis as well, if action is not taken. The mental health and wellbeing of whole societies have been severely impacted by this crisis and are a priority to be addressed urgently."

United Nations Policy Brief: COVID-19 and the Need for Action on Mental Health, May 2020.

Whereas COVID pandemic has emerged with a high psychological impact on populations in general, worldwide, it has been reported by the CDC that over one third of adult patients hospitalized with COVID-19, were respiratory related such as COPD [38]. In a systematic review and meta-analysis, Gerayeli et al found that having a clinical diagnosis of COPD significantly increases the odds of poor clinical outcomes in patients with COVID-19 [39]. In the first nationwide population study to evaluate the impact of COPD on the clinical characteristics and prognosis of COVID-19 patients in South Korea, COPD was not an independent risk factor for respiratory failure, although it was a significant risk factor all-cause mortality [40]. It was demonstrated, in a Swedish study, that the elderly population has an increased vulnerability to stressful situations that can impact their well-being greatly. The half of the participants stated that forced isolation and social distancing affect their mental health. [41].

Umberson and Montez argue that the "Social isolation of otherwise healthy, well-functioning individuals eventually results in psychological and physical disintegration, and even death" [42]. While there is emerging evidence that COPD is a physical condition with social consequences, the COPD patients with comorbid anxiety and depression, in the prevailing COVID19 pandemic, are quite likely to present with worsening symptoms, because of home isolation and social distancing. This is even more true in elderly patients who, often with pre-existing mobility limitations, now find themselves "trapped in their own homes", potentially triggering hopelessness and even suicidal ideation. [43].

While discussing the "The Mental Health Consequences of COVID-19 and Physical Distancing", Sandro Galea et al argued that instituting the practice of social distancing may be critical to mitigate the spread of the disease but it will undoubtedly have consequences for mental health and well-being in both the short and long term [44]. In a cross-sectional study, conducted at a pulmonology clinic in Santa Marta, Colombia, prevalence of high COVID-19 perceived stress was $10.6 \%$, post-traumatic stress risk $11.3 \%$, depression risk $31.5 \%$ and insomnia risk $57.7 \%$ amongst patients with COPD, aged 18-96 years. [45]. This should not be surprising because "We have a real opportunity, a natural experiment, in how policies in different countries impact people's mental health," as remarked by Kathleen Merikangas, Epidemiologist at the US National Institutes of Mental Health in Bethesda, Maryland.

In a "Life Stressors Impact on Mental Health and Well-being Survey ", to assess the burden of depression among US adults during COVID -19 Pandemic, it was found that the prevalence increased more than three fold higher, from $8.5 \%$ before COVID-19 to $27.8 \%$ during COVID-19. Moreover, it was 7.5-fold higher for severe depression symptoms category [46]. In the UK people with COPD (and other severe respiratory conditions) were among those defined as "extremely clinically vulnerable" and advised to "socially shield", avoiding all face- to-face contact for at least 12 weeks in the first instance [47]. What was the "aftereffect"? The findings from the first wave of data collection from a community cohort study established in the UK to prospectively examine the mental health consequences of the COVID-19 pandemic, revealed that $64 \%$ of participants reported symptoms of depression, $31.6 \%$ were of moderate to severe depression [48]. Boiutou et al have concluded that "shielding" has further exacerbated physical activity decline, shown through a $39 \%$ reduction in daily steps from post-pulmonary rehabilitation to shielding (3 months) [49]. It is known that physical inactivity and deconditioning can often lead to worsening of symptoms in COPD and subsequent deterioration of physical functioning and HRQoL [50] along with an increased risk of hospitalizations and mortality [51]

\section{How to Cope with the Prevailing Situation?}

In the context of the COVID-19 pandemic, it appears likely that there will be substantial increases in depression associated COPD equilateral is dire need to search for an effective interventional strategy. Following are the suggestions:

\section{(a) - The Psychological First Aid Guidance}

Mental Health UK has described the "The 6 Ways to Boost One's Well-being While Staying Indoors" [52] which are easily doable and really well-rewarding.

A. Connect with others: through WhatsApp, Skype and Facebook or even an old-fashioned phone call. Having a Netflix Watch Party with friends would be an innovative idea. Those skilled in some specialty may make the best of time by organizing online sessions on the topics of mutual interest.

B. Be physically active: through permissible outdoor exercise or indoor gym (if space is available) and online Yoga and fitness classes.

C. Be mentally active: through playing board games, games like Ticket to Ride, Settlers of Catan and Scrabble. Helping children (if at home) in their homework or offering any assistance to the parents (if at home) or through Skype or Whats App (if they are living independently) would be highly appreciated.

D. Learn new skills: through the material available online and the friends to improve mental wellbeing. Learning crafts such as knitting and crochet, drawing and painting would be well rewarding.

E. Mindfulness: through paying more attention to the present moment with practice and concentration. Subscription to "Mental Health Moments" would be very fruitful.

F. Give to others: through signing up to one of the local Mutual Aid groups, donating food to a food-bank or using an app like nextdoor to connect to local community or by giving a call for chat to those who are self-isolating and alone at home.

(b) - WHO's Unique Contribution: The "Living with the Times" toolkit containing illustrated posters with key messages for older adults on how to maintain their well-being during the COVID-19 pandemic, is a unique potentially beneficial approach [53].

(c) - Novel Add-ons: Dance Movements Therapy (DMT) and Musical Engagement Therapy have emerged as promising effective Add-ons in the management of COPD and depression and are worth trial in the prevailing situation. [54, 55].

DMT has aesthetic expression, attractive to both genders irrespective of age, tempting to those with disabilities, and a fruitful tool in developing self-confidence. [54]. Certain Organizations of National and International Disability, provide ample opportunities for disabled and would be of special interest to COPD patients, with disabilities, planning to avail the benefits of DMT. Solo dancing, while restricted to home, is a highly accessible, doable, feasible, sustainable and beneficial alternative. Online group-sessions for dance are available for those, willing to join.Interestingly, The Bezmialem Vakif University Istanbul Turkey has 
championed to initiate "The First Interventional (Clinical Trial) Study to Apply Dance-based Exercise Training in COPD" - with the goal to "to investigate the effect of creative dance-based exercise training on respiratory, balance and cognitive functions, respiratory and peripheral muscle strength and functional capacity in COPD patients".

Music therapy (singing and listening), an inexpensive and readily accessible resource, has emerged as promising interventional strategy, with acceptance on wider scale, because of its unique link to the emotions and powerful soothing effect [55]. In a systematic review and metaanalysis of 26 studies, a statistically significant reduction in depression levels was found over time in the experimental (music intervention) group compared to a control / comparison group. In particular, elderly participants showed impressive improvements when they listened to music or participated in music therapy projects [56]. Of imp, in the Clinical Trials. gov entitled "Active and Passive Music Therapy Interventions", sponsored by University of North Carolina Chapel Hill United States, it has been argued that: "Music therapy (MT) interventions are a cost-effective, accessible, and holistic treatment option with social, rhythmic, creative, sensorimotor, and respiratory components, giving them the potential to improve the quality of life for a diverse array of disorders".

\section{Conclusion}

"COPD is an individual disease, I have yet to meet any two people with $C O P D$ would have the exact same symptoms and have reacted exactly the same to this horrible disease".

Mary Clara Ultes (1946-2018)-- "Same Devil - Different Levels, Same Level - Different Devils"

Prevalence studies show that patients who have COPD are four times as likely to develop depression compared to those without COPD. Regrettably, this dual burden is under-recognized and under-treated. Pumar et al have argued that, in daily practice, the presence of psychological manifestations in patients with COPD is often regarded as a complication caused by the physical ailments [57]. Whereas it is known that pulmonary rehabilitation (PR) alleviates depression in patients with COPD and a reduction of depressive symptoms makes PR more effective, and patient are more motivated to cooperate actively with the therapist in the rehabilitation process [11],they are still under- referred, by the health care providers. A tailored, cognitive behavioral approach (CBA) intervention has been developed for patients with COPD and co- morbid anxiety and/or depression. This has been named TANDEM (Tailored intervention for Anxiety and Depression Management in COPD): Protocol for a Randomized Controlled Trial), and has been sponsored by Queen Mary, University of London. This trial would, most hopefully, optimize the unrealized synergy between a psychological intervention and PR. [58]. The fittest closing sentence is from"COPD Makes Things Harder, But Life is Fun"--

"Don't despair. Life is not over. It is just more challenging”.

\section{Acknowledgements}

The authors are highly grateful to Prof. Nicolino Ambrosino Respirologist (Italy) and Prof. Amin Muhammad Gadit Clinical Professor of Psychiatry (Canada) for their scholarly advice to improve the manuscript.

The authors express great appreciation to Dr. Murad Ahmad Khan (Vancouver, BC) for his insightful suggestions and stimulating discussions, throughout the conduct of this study.

\section{Competing Interests}

The authors declare that they have no direct and indirect financial, commercial, personal/career affiliation with the article, counting any individually held viewpoint that are relevant to their work, to disclose.

\section{Funding:}

The authors received no financial support, from any quarter, for the research, authorship, and/or publication of this article.

\section{References}

1. Duffy S, Weir M, Criner GJ. (2015) The complex challenge of chronic obstructive pulmonary disease. Lancet Respir Med. 3(12):917-9. doi: 10.1016/S2213-2600(15)00480-4.

2. Johnson KM, Safari A, Tan WC, Bourbeau J, FitzGerald JM, Sadatsafavi M. (2018) Heterogeneity in the respiratory symptoms of patients with mild-to-moderate COPD. Int J Chron Obstruct Pulmon Dis. 13:3983-3995.

3. Faner R, Agustí Á. Multilevel, (2016) Dynamic Chronic Obstructive Pulmonary Disease Heterogeneity. A Challenge for Personalized Medicine. Ann Am Thorac Soc. 13 Suppl 2:S466-S470.

4. Houben-Wilke S, Augustin IM, Vercoulen JH, van Ranst D, Bij de Vaate E, et al. (2018) COPD stands for complex obstructive pulmonary disease. Eur Respir Rev. 27(148):180027. doi: 10.1183/16000617.0027-2018.

5. Tavormina R, Tavormina MGM. (2018) Overcoming Depression with Dance Movement Therapy: A Case Report. Psychiatr Danub. 30(Suppl 7):515-520.

6. WHO-Depression and Other Common Mental Disorders: Global Health Estimates-World Health Organization 2017 WHO/MSD/MER/2017.2

7. American Psychiatric Association. Diagnostic and Statistical Manual of Mental Disorders (DSM-5)-Arlington, American Psychiatric Association, 2013.5th Edition

8. Norwood RJ. (2007) A review of etiologies of depression in COPD Int J Chron Obstruct Pulmon Dis. 2(4):485-491.

9. Barnes PJ, Celli BR. (2009) Systemic manifestations and comorbidities of COPD. Eur Respir J. 33(5):1165-85. doi: 10.1183/09031936.00128008. PMID: 19407051.

10. Tselebis A., Pachi, A., Ilias I., Kosmas E., Bratis D., Moussas, G.,Tzanakis, N. (2016) Strategies to improve anxiety and depression in patients with COPD: a mental health perspective. Neuropsychiatric disease and treatment, 12, 297-328.

11. Panagioti M, Scott C, Blakemore A, Coventry PA. (2014) Overview of the prevalence, impact, and management of depression and anxiety in chronic obstructive pulmonary disease. Int $J$ Chron Obstruct Pulmon Dis. 9:1289-306. doi: 10.2147/COPD.S72073.

12. van Manen JG, Bindels PJ, Dekker FW, IJzermans CJ, van der Zee JS, Schadé E. (2002) Risk of depression in patients with chronic obstructive pulmonary disease and its determinants. Thorax. 57(5):412-6. doi: 10.1136/thorax.57.5.412.

13. Schneider C, Jick SS, Bothner U, Meier CR. (2010) COPD and the risk of depression. Chest. 137(2):341-7. doi: 10.1378/chest.09-0614.

14. Li W, Pu Y, Meng A, Zhi X, Xu G. (2019) Effectiveness of pulmonary rehabilitation in elderly patients with COPD: A systematic review and meta-analysis of randomized controlled trials. Int J Nurs Pract. 25(5):e12745. doi: 10.1111/ijn.12745.

15. Gut-Gobert C, Cavaillès A, Dixmier A, Guillot, S., Jouneau, S. et al (2019) Women and COPD: do we need more evidence? Eur Respir Rev, 28: 180055.

16. Wrzeciono,A.;Czech,O.; Buchta, K.; Zabłotni, S.; Gos, E.; et al. (2021) Assessment of Stress, Depressive and Anxiety Symptoms in Patients with COPD during In-Hospital Pulmonary Rehabilitation: An Observational Cohort Study. Medicina, 57, 197. 
17. Dalal AA, Shah M, Lunacsek O, Hanania NA. (2011) Clinical and economic burden of depression/anxiety in chronic obstructive pulmonary disease patients within a managed care population. COPD. 8(4):293-9. doi: 10.3109/15412555.2011.586659.

18. Ng TP, Niti M, Tan WC, Cao Z, Ong KC, Eng P. (2007) Depressive symptoms and chronic obstructive pulmonary disease: effect on mortality, hospital readmission, symptom burden, functional status, and quality of life. Arch Intern Med. 167(1):60-7. doi: 10.1001/archinte.167.1.60.

19. de Voogd JN, Wempe JB, Koëter GH, Postema K, van Sonderen E, Ranchor AV, Coyne JC, Sanderman R. (2009) Depressive symptoms as predictors of mortality in patients with COPD. Chest. 135(3):619625. doi: 10.1378/chest.08-0078.

20. van Ede L, Yzermans CJ, Brouwer HJ. (1999) Prevalence of depression in patients with chronic obstructive pulmonary disease: a systematic review. Thorax. 54(8):688-92. doi: 10.1136/thx.54.8.688.

21. Atlantis E, Fahey P, Cochrane B, Smith S. (2013) Bidirectional associations between clinically relevant depression or anxiety and COPD: a systematic review and meta-analysis. Chest. 144(3):766777. doi: 10.1378/chest.12-1911.

22. Xu W, Collet JP, Shapiro S, Lin Y, Yang T, Platt RW, Wang C, Bourbeau J. (2008) Independent effect of depression and anxiety on chronic obstructive pulmonary disease exacerbations and hospitalizations. Am J Respir Crit Care Med. 178(9):913-20. doi: 10.1164/rccm.200804-619OC.

23. DiMatteo MR, Lepper HS, Croghan TW. (2000) Depression is a risk factor for noncompliance with medical treatment: meta-analysis of the effects of anxiety and depression on patient adherence. Arch Intern Med. 160(14):2101-7. doi: 10.1001/archinte.160.14.2101.

24. Laurin C, Moullec G, Bacon SL, Lavoie KL. (2012) Impact of anxiety and depression on chronic obstructive pulmonary disease exacerbation risk. Am J Respir Crit Care Med. 185(9):918 -23. doi: 10.1164/rccm.201105-0939PP.

25. Coventry PA, Gemmell I, Todd CJ. (2011) Psychosocial risk factors for hospital readmission in COPD patients on early discharge services: a cohort study. BMC Pulm Med. 2011 Nov 4;11:49. doi: 10.1186/1471-2466-11-49.

26. Antoniu SA, Petrescu E, Stanescu R, Anisie E, Boiculese L. (2016) Impact of fatigue in patients with chronic obstructive pulmonary disease: results from an exploratory study. Ther Adv Respir Dis. 10(1):26-33. doi: 10.1177/1753465815617707.

27. Webb RT, Kontopantelis E, Doran T, Qin P, Creed F, Kapur N (2012) Suicide risk in primary care patients with major physical diseases: a case-control study. Arch Gen Psychiatry. 69(3):256-64. doi: 10.1001/archgenpsychiatry.2011.1561.

28. Miravitlles M, Molina J, Quintano JA, Campuzano A, Pérez J, Roncero C. (2014) DEPREPOC Study Investigators. Factors associated with depression and severe depression in patients with COPD. Respir Med. 108(11):1615-25. doi: 10.1016/j.rmed.2014.08.010.

29. Goodwin RD. (2011) Is COPD associated with suicide behavior? J Psychiatr Res. 45(9):1269-71. doi: 10.1016/j.jpsychires.2011.01.014.

30. Fleehart S, Fan V, Nguyen HQ, Lee J, Kohen R, et a. (2014) Prevalence and correlates of suicide ideation in patients with COPD: a mixed methods study. Int J Chron Obstruct Pulmon Dis. 9(1):1321-1329

31. Lin CY, Harnod T, Lin CL, Kao CH. (2020) Suicide Attempt and Suicidal Drug Overdose in Chronic Obstructive Pulmonary Disease Patients with or Without Depression. Front Psychiatry. 11:270. doi: 10.3389/fpsyt.2020.00270.

32. Chung JH, Han CH, Park SC, Kim CJ. (2014) Suicidal ideation and suicide attempts in chronic obstructive pulmonary disease: the Korea National Health and Nutrition Examination Survey (KNHANES IV,
V) from 2007-2012. NPJ Prim Care Respir Med. 24:14094. doi: 10.1038/npjpcrm.2014.94

33. Strid JM, Christiansen CF, Olsen M, Qin P. (2014) Hospitalisation for chronic obstructive pulmonary disease and risk of suicide: a population-based case-control study. BMJ Open. 4(11):e006363. doi: 10.1136/bmjopen-2014-006363.

34. Wong TS, Xiang YT, Tsoh J, Ungvari GS, Ko FW, Hui DS, Chiu HF. (2014) Depressive disorders in older patients with chronic obstructive pulmonary disease (COPD) in Hong Kong: a controlled study. Aging Ment Health. 18(5):588-92. doi: 10.1080/13607863.2013.856862.

35. Spitzer RL, Williams JB, Kroenke K, Linzer M, deGruy FV 3rd, Hahn SR, Brody D, Johnson JG. (1994) Utility of a new procedure for diagnosing mental disorders in primary care. The PRIME-MD 1000 study. JAMA. 272(22):1749-56.

36. NICE- Chronic Obstructive Pulmonary Disease in over 16: Diagnosis and Management (NG 115)- NICE 2020; 1-69

37. Hananis NA, Müllerova H, Locantore NW, Vestbo J, Watkins ML et al. (2011) Evaluation of COPD Longitudinally to Identify Predictive Surrogate Endpoints (ECLIPSE) study investigators. Determinants of depression in the ECLIPSE chronic obstructive pulmonary disease cohort. Am J Respir Crit Care Med. 183(5):60411. doi: $10.1164 / \mathrm{rccm} .201003-0472 \mathrm{OC}$.

38. Garg S, Kim L, Walker M, et al. (2020) Hospitalization rates and characteristics of patients hospitalized with laboratory-confirmed corona- virus disease 2019 - COVID-NET, 14 states. MMWR. 2020;69:1-7.

39. Gerayeli FV, Milne S, Cheung C, Li X, Yang CWT, Tam A, Choi LH, Bae A, Sin DD. (2021) COPD and the risk of poor outcomes in COVID-19: A systematic review and meta-analysis. E Clinical Medicine. 33:100789. doi: 10.1016/j.eclinm.2021.100789.

40. Lee, S.C., Son, K.J., Han, C.H. et al. (2021) Impact of COPD on COVID-19 prognosis: A nationwide population-based study in South Korea. Sci Rep 11, 3735.

41. Gustavsson J, Beckman L. (2020) Compliance to Recommendations and Mental Health Consequences among Elderly in Sweden during the Initial Phase of the COVID-19 Pandemic-A Cross Sectional Online Survey. Int J Environ Res Public Health. 17(15):5380. doi: 10.3390/ijerph17155380.

42. Umberson D, Montez JK. (2010) Social Relationships and Health: A Flashpoint for Health Policy -J Health Soc Behav. 51(Suppl): S54 S66. doi:10.1177/0022146510383501.

43. Yohannes AM. (2021) COPD patients in a COVID-19 society: depression and anxiety. Expert Rev Respir Med. 15(1):5-7. doi: 10.1080/17476348.2020.1787835.

44. Galea S, Merchant RM, Lurie N. (2020) The Mental Health Consequences of COVID-19 and Physical Distancing: The Need for Prevention and Early Intervention. JAMA Intern Med. 180(6):817818. doi: 10.1001/jamainternmed.2020.1562.

45. Pedrozo-Pupo JC, Campo-Arias A. (2020) Depression, perceived stress related to COVID, post-traumatic stress, and insomnia among asthma and COPD patients during the COVID-19 pandemic. Chron Respir Dis. 17:1479973120962800.

46. Esteban C, Quintana JM, Aburto M, Moraza J, Egurrola M, et al. (2010) Impact of changes in physical activity on health-related quality of life among patients with COPD. Eur Respir J. 36(2):292300. doi: 10.1183/09031936.00021409.

47. Kmietowicz Z. (2020) Covid-19: Highest risk patients are asked to stay at home for 12 weeks. BMJ. 368:m1170. doi: 10.1136/bmj.m1170.

48. Jia R, Ayling K, Chalder T, Massey A, Broadbent E, Coupland C, Vedhara K. (2020) Mental health in the UK during the COVID-19 pandemic: cross-sectional analyses from a community cohort study. BMJ Open. 10(9):e040620. doi: 10.1136/bmjopen-2020-040620. 
49. Boutou AK, Raste Y, Demeyer H, Troosters T, Polkey MI, et al. (2019) Progression of physical inactivity in COPD patients: the effect of time and climate conditions - a multicenter prospective cohort study. Int J Chron Obstruct Pulmon Dis. 14:1979-1992.

50. Troosters T, van der Molen T, Polkey M, Rabinovich RA, Vogiatzis I, Weisman I, Kulich K. (2013) Improving physical activity in COPD: towards a new paradigm. Respir Res. 14(1):115. doi: 10.1186/1465-9921-14-115.

51. Garcia-Aymerich J, Lange P, Benet M, Schnohr P, Antó JM. (2006) Regular physical activity reduces hospital admission and mortality in chronic obstructive pulmonary disease: a population based cohort study. Thorax. 61(9):772-8.

52. Mental Health UK-Managing your mental health during the coronavirus outbreak.

53. WHO - Living with the Time:New Tool Kit.

54. Khan I A. (2020) Dance Movement Therapy: A Promising Lifestyle Intervention in the Management of Chronic Obstructive Pulmonary Disease, J Integ Med, 8(2): 13-18
55. Khan I A. (2021) Musical Engagement Therapy: An Effective Addon in the Management of Chronic Obstructive Pulmonary Disease, Medicina Universitaria, 23(1):11-17

56. Leubner D, Hinterberger T. (2017) Reviewing the Effectiveness of Music Interventions in Treating Depression-Front. Psychol. 1109 doi:10.3389/fpsyg.2017.01109

57. Pumar MI, Gray CR, Walsh JR, Yang IA, Rolls TA, Ward DL. (2014) Anxiety and depression-Important psychological comorbidities of COPD. $J$ Thorac Dis. 6(11):1615-31.doi: 10.3978/j.issn.2072-1439.2014.09.28.

58. Sohanpal R, Pinnock H, Steed L, Heslop Marshall K, Chan C, et al. (2020) TANDEM Investigators. Tailored, psychological intervention for anxiety or depression in people with chronic obstructive pulmonary disease (COPD), TANDEM (Tailored intervention for ANxiety and DEpression Management in COPD): protocol for a randomised controlled trial. Trials. 21(1):18.

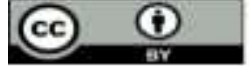

This work is licensed under Creative Commons Attribution 4.0 License

To Submit Your Article Click Here: Submit Manuscript

DOI: $10.31579 / 2690-8794 / 095$
Ready to submit your research? Choose Auctores and benefit from:

> fast, convenient online submission

$>$ rigorous peer review by experienced research in your field

$>$ rapid publication on acceptance

$>$ authors retain copyrights

$>$ unique DOI for all articles

> immediate, unrestricted online access

At Auctores, research is always in progress.

Learn more www.auctoresonline.org/journals/clinical-medical-reviewsand-reports 